\title{
The Continuance Intention of User's Engagement in Multiplayer Video Games based on Uses and Gratifications Theory
}

\author{
Ira Puspitasari ${ }^{1,2)^{*}}$, Elzha Odie Syahputra ${ }^{3)}$, Indra Kharisma Raharjana ${ }^{4)}$, Ferry Jie ${ }^{5 \text { ) }}$ \\ 1)314) Information Systems Study Program, Universitas Airlangga \\ Surabaya, Indonesia \\ 1) ira-p@fst.unair.ac.id \\ 3) elzha.odie.syahputra-2014@fst.unair.ac.id \\ 4) indra.kharisma@fst.unair.ac.id \\ ${ }^{2)}$ Research Center for Quantum Engineering Design, Universitas Airlangga \\ Surabaya, Indonesia \\ 2) ira-p@fst.unair.ac.id \\ ${ }^{5)}$ School of Business and Law, Edith Cowan University \\ Joondalup, Australia \\ 5)f.jie@ecu.edu.au
}

Article history:

Received 12 August 2018

Revised 30 September 2018

Accepted 7 October 2018

Available online 28 October 2018

Keywords:

Continuation intention Multiplayer video game Uses and Gratifications Theory

User's engagement

Partial Least Square

\section{Abstract}

One of the key success factors in video game industry, including multiplayer video game (MVG), is the user's continuance intention. The MVG industry runs in a highly competitive market. Users can shift to another game as soon as they discover a slightly inconvenient issue. Thus, maintaining the user's enthusiasm in playing MVG for a long time is challenging for most games. The solution to prolong the users' engagement can be initiated by identifying all factors that facilitate the continuance use of playing MVG. This study applied uses and gratifications theory to examine seven variables (enjoyment, fantasy, escapism, social interaction, social presence, achievement, and self-presentation) and the moderating effects of age and gender on the MVG continuance intention. The data analysis and the model development were tested based on Partial Least Square method using the responses of 453 MVG users. The results revealed that enjoyment, fantasy, social interaction, achievement, and self-presentation significantly affected the continuance intention of playing MVG, with enjoyment being the strongest variable. The result also demonstrated the moderating effect of age and gender on the relation between independent variables and continuance intention. The results and findings offered additional insights into the system development to enhance the information system application.

\section{INTRODUCTION}

One of the most essential technological innovations that have been integrated in human lives is information systems. The information systems have been utilized in almost all aspects of business, government, health, culture, education, and entertainment. All variations of information systems are classifiable into utilitarian and hedonic

\footnotetext{
${ }^{*}$ Corresponding author
} 
information systems [1]. The utilitarian information systems provide goal-oriented and focus to user productivity, whilst hedonic information systems emphasize the entertainment purpose. While the utilitarian systems have dominated the industry evolution, the development of hedonic information systems have risen over the past few years.

One of the most developed and widely-used hedonic information systems is multiplayer video game (MVG). This game rapidly expands as it offers entertainment, social interaction, and economic benefits. MVG enables multiple users to play game at the same time in the same environment and involves cooperation and/or competition interactions among the users [2], [3]. People play MVG for enjoyment and relaxation, to fulfil behavioral needs related to achievement and competition, and to earn rewards and incentive benefits. As the internet and social media technologies have advanced rapidly, a large number of multiplayer video games have been released and the game publisher have shifted the mechanism of game play from pay-to-play to free-to-play or pay-for-additional features [4]. Some examples of popular MVGs are World of Warcraft, DOTA, and Mobile Legends. The number of online game players has increased at a rapid rate as well. This situation has led to a competitive market for online games, especially multiplayer video games. The users or gamers can shift to another game as soon as they discover a slightly inconvenient issue [5]. They may change to another game because they simply want to try new game experiences [6], they find unresolved technical problems (e.g., error, flat game scenario), or they perceived that they have finished all challenges in the game. Therefore, keeping the users to play the same game for a long time becomes more challenging for most games. The solutions to prolong the users' engagement can be initiated by identifying all contributing factors that facilitates the continuance use of a system.

Previous works have examined the behavioral factors that influenced the acceptance [7], [8], adoption [9], [10], and continuance use [11], [12] of a system. In the case of multiplayer video games (MVG), where the game play supports individual achievement and includes social interaction between players, it is appropriate to examine the gamers' engagement based on uses and gratifications theory (UGT). UGT is a sociological theory that describes why and how people actively seek out specific media to satisfy specific needs [13]. Recent works have studied UGT to analyze the continuance use of computer-based media and computer-mediated communication [14], [15]. Based on uses and gratifications theory, the motivations to play MVG, the success of playing the game, and the gratifications achieved predict the continuance use of MVG.

To develop a robust solution for user's engagement problems, this study aims to identify the factors that affect the continuance intention of playing multiplayer video games based on uses and gratifications theory. The output of this study could provide recommendation for the game developers on how to increase user retention and loyalty. Additionally, this study assesses further the contributing factors by considering multiple aspects and explores its relevance to the hedonic information systems field. Research on the continuance intention of MVG may also have implications for increasing the success of information systems in general.

\section{Methods}

The continuance intention of playing video game is affected by three gratifications, i.e. hedonic gratification (enjoyment, fantasy and escapism), utilitarian gratification (achievement and self-presentation) and social gratification (social interaction and social presence) [5]. We adopted $\mathrm{H}$. Li et al. [5] approach to examine the contributing factors that affect users in playing multiplayer video game in the following six steps. The first step was determining the research model based on uses and gratifications theory, as presented in Fig. 1. The model consisted of seven variables, i.e., enjoyment, fantasy, escapism, social interaction, social presence, achievement, and selfpresentation. The users perceive enjoyment when they can enjoy playing the game and interacting with other users. Fantasy allows the users to carry out activities that are not possible to do in the real world, such as transforming into imaginary characters and possessing magical abilities. Next, escapism allows the users to be immersed in the game environment to escape from the stresses of daily life. In the case of social interaction, MVG is considered as one of social places, where the users can develop social relationships and receive feedback from other users [16]. MVG also facilitates the communication between users via synchronization messages and other communication channels to denote social presence. Achievement in MVG involves challenges in the game-play that motivate the users to continue the game engagement. Lastly, self-presentation facilitates the development of self-image to others.

The methods continued with constructing the hypotheses. Based on the research model, this study applied the following hypotheses.

H1: enjoyment positively impacts the continuance intention of playing MVG

$\mathrm{H} 2$ : fantasy positively impacts the continuance intention of playing MVG

$\mathrm{H} 3$ : escapism positively impacts the continuance intention of playing MVG

$\mathrm{H} 4$ : social interaction positively impacts the continuance intention of playing MVG 
H5: social presence positively impacts the continuance intention of playing MVG

H6: achievement positively impacts the continuance intention of playing MVG

H7: self-presentation positively impacts the continuance intention of playing MVG

This study also investigated two demographic profiles, age and gender, as the moderating variables on the MVG continuance intention.

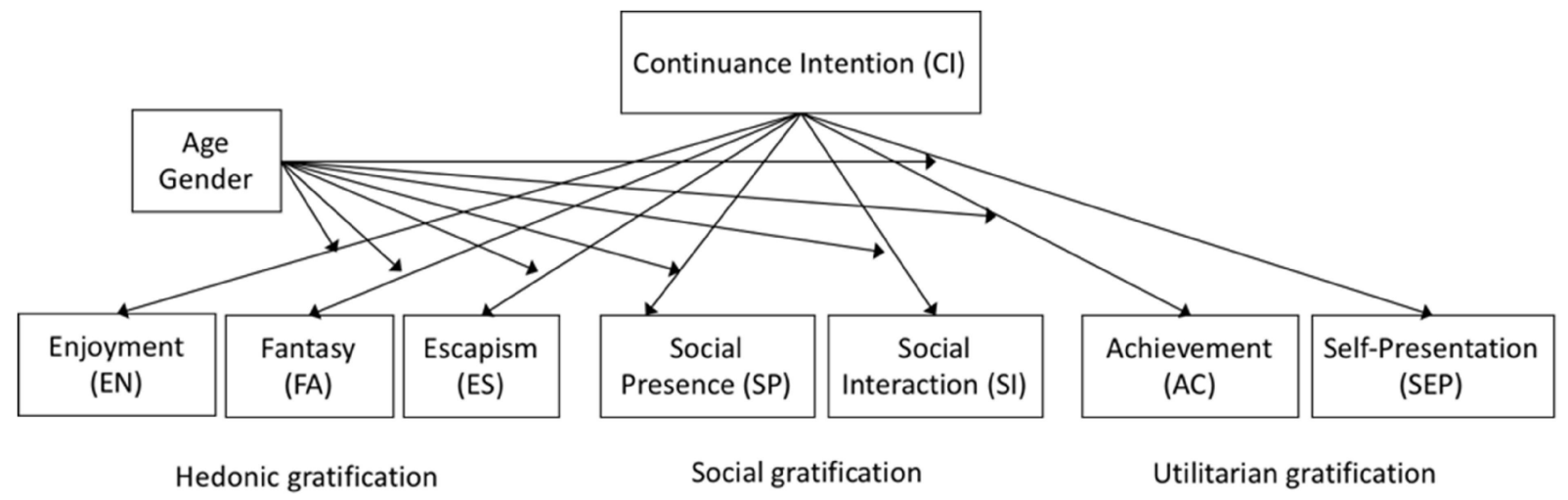

Fig. 1 The research model based on Uses and Gratifications Theory (adopted from [5])

The third step was collecting the data using online and offline (paper-based) questionnaires that consisted of demographics profiles and behavioral questions. The questionnaire was developed based on uses and gratifications theory instruments. The behavioral intention and all exogenous constructs were measured using 5-point Likert scale, i.e., strongly disagree (1), disagree (2), neutral (3), agree (4), and strongly agree (5). The recruited respondents were gamers with a minimum age of 18 years and had experiences of playing at least one MVG. The data collected from the participants was processed further in three phases, i.e., data tabulation, evaluation of the measurement model, and evaluation of the structural model. The data tabulation portrays the demographic profiles and described the respondents' answers. Evaluation of the measurement model tested the validity and reliability of the constructs. The last evaluation checked all data against structural equation modeling to determine the acceptance of the hypotheses. Drawing on the structural model evaluation, we analyzed the results and proposed recommendations pertaining to the users' continuance intention of playing multiplayer video game.

TABLE I

DEMOGRAPHICS PROFILE OF THE RESPONDENTS

\begin{tabular}{lc}
\hline \multicolumn{2}{c}{ DEMOGRAPHICS PROFILE OF THE RESPONDENTS } \\
\hline \hline Category & $\mathbf{N}(\mathbf{\%}) \mathbf{, ~} \mathbf{=}=\mathbf{4 5 3}$ \\
\hline Mender & $325(71.7)$ \\
Female & $128(28.3)$ \\
Age & \\
$<16$ years & $32(7.1)$ \\
$16-20$ years & $208(45.9)$ \\
$21-25$ years & $213(47.0)$ \\
Frequency of playing MVG & \\
Few times a day & $276(60.9)$ \\
Once a day & $63(13.9)$ \\
Few times a week & $93(20.5)$ \\
Once a week & $21(4.6)$ \\
Last playing MVG & \\
$<1$ month & $378(83.4)$ \\
$1-2$ months & $22(4.9)$ \\
$>2-3$ months & $10(2.2)$ \\
$>3$ months & $43(9.5)$ \\
\hline \hline
\end{tabular}

\section{RESULTS}

\section{A. Demographic Profile of Respondents}

A total of 465 respondents participated in the data collection, but only 453 responses were valid and included in the next data processing. The majority of the participants were male (71.7\%). This gender profile confirmed prior studies that reported the majority of multiplayer video games were male [2], [5]. More than half of the participants 
played MVG few times a day (60.9\%) with the last playing time was less than one month (83.4\%). Table I presents the demographic profile of the respondents.

\section{B. Evaluation of the measurement model (outer model)}

The evaluation of the measurement model consisted of validity test (convergent validity and discriminant validity) and reliability test. In a convergent validity test, the construct was valid if the loading factor $>0.7$ [17]. Based on the convergent validity test in Table II, 23 indicators were valid, and 4 indicators were not valid. The validity test was repeated by eliminating the indicators with loading factor score below 0.7 . The second validity test showed all indicators were valid (loading factor $>0.7$ ), as shown in Table III. For discriminant validity test, the correlation value between two constructs was less than the square roots of the average variation extracted (AVE) of each construct, indicating a favorable discriminant validity.

TABLE II

CONSTRUCT, MEASUREMENT ITEM, AND LOADING FACTOR

\begin{tabular}{|c|c|c|c|}
\hline Construct & Indicator & Measurement Item & Loading Factor \\
\hline \multirow{3}{*}{ Enjoyment } & EN1 & I am interested in playing MVG & 0.889 \\
\hline & EN2 & I enjoy playing MVG & 0.935 \\
\hline & EN3 & I am happy playing MVG & 0.926 \\
\hline \multirow{3}{*}{ Fantasy } & FA1 & I play MVG to experience things I cannot experience in real life & 0.829 \\
\hline & FA2 & I play MVG to act as another character & 0.683 \\
\hline & FA3 & I play MVG to immerse myself in the game environment & 0.861 \\
\hline \multirow[t]{4}{*}{ Escapism } & ES1 & I play MVG whenever I feel frustrated & 0.784 \\
\hline & ES2 & I like playing MVG when I experience a bad day & 0.787 \\
\hline & ES3 & I can let my anger out when I play MVG & 0.738 \\
\hline & ES4 & Playing MVG is the best way to temporarily escape from the real world & 0.681 \\
\hline Social & SI1 & I open more myself to others using MVG than via other communication media & 0.668 \\
\hline \multirow{3}{*}{ Interaction } & SI2 & I have many friends by playing MVG & 0.771 \\
\hline & SI3 & Playing MVG allows me to connect with my friends in the real world & 0.835 \\
\hline & SI4 & Playing MVG allows me to keep in touch with my friends in the real world & 0.738 \\
\hline Social & SP1 & I believe that another gamer will help me whenever I am in trouble & 0.670 \\
\hline \multirow[t]{3}{*}{ Presence } & SP2 & I feel connected with other gamers when I play MVG & 0.766 \\
\hline & SP3 & I can be myself and I can show my real game-play to others in MVG environment & 0.815 \\
\hline & SP4 & I feel I am the member of a MVG community during the game playing & 0.750 \\
\hline \multirow{4}{*}{ Achievement } & $\mathrm{AC} 1$ & I play MVG to reach higher levels & 0.826 \\
\hline & $\mathrm{AC} 2$ & I play MVG to get more power than other gamers & 0.880 \\
\hline & $\mathrm{AC} 3$ & $\begin{array}{l}\text { I play MVG to have items or equipment that allow me to achieve higher position } \\
\text { than other gamers }\end{array}$ & 0.802 \\
\hline & $\mathrm{AC} 4$ & I play MVG to show to other gamers that I am the best & 0.794 \\
\hline Self- & SEP1 & I play MVG because I want other gamers recognize me as a cool gamer & 0.807 \\
\hline \multirow[t]{2}{*}{ presentation } & SEP2 & I play MVG because I want other gamers perceive me as friendly & 0.826 \\
\hline & SEP3 & I play MVG because I want other gamers acknowledge my skill & 0.936 \\
\hline Continuance & CI1 & Playing MVG is worthy & 0.896 \\
\hline Intention & $\mathrm{CI} 2$ & I am willing to play MVG in the near future & 0.884 \\
\hline
\end{tabular}

TABLE III

\begin{tabular}{ccccccccccc}
\multicolumn{10}{c}{ RELIABILITY TEST } \\
\hline \hline Construct & Composite Reliability & AVE & AC & CI & EN & ES & FA & SEP & SI & SP \\
\hline AC & 0,896 & 0.683 & $\mathbf{0 . 8 2 6}$ & & & & & & \\
CI & 0,884 & 0.792 & 0.414 & $\mathbf{0 . 8 9 0}$ & & & & & \\
EN & 0,941 & 0.841 & 0.333 & 0.518 & $\mathbf{0 . 9 1 7}$ & & & & \\
ES & 0,876 & 0.703 & 0.251 & 0.194 & 0.184 & $\mathbf{0 . 8 3 8}$ & & & \\
FA & 0,847 & 0.734 & 0.349 & 0.359 & 0.330 & 0.316 & $\mathbf{0 . 8 5 7}$ & & \\
SEP & 0,893 & 0.736 & 0.482 & 0.161 & 0.166 & 0.269 & 0.303 & $\mathbf{0 . 8 5 8}$ & \\
SI & 0,857 & 0.668 & 0.289 & 0.478 & 0.464 & 0.229 & 0.351 & 0.258 & $\mathbf{0 . 8 1 7}$ & \\
SP & 0,835 & 0.628 & 0.381 & 0.445 & 0.492 & 0.255 & 0.451 & 0.272 & 0.531 & $\mathbf{0 . 7 9 2}$ \\
\hline \hline
\end{tabular}

Note: the bold number is the square root of AVE. The subsequent numbers below the bold number in the same column show the correlation value between two constructs.

The reliability test was evaluated based on the composite reliability and AVE scores. The composite reliability checked the internal consistency, while AVE measured the amount of variance that is captured by a construct relative to the amount of variance due to measurement error [18], [19]. The favorable reliability is achieved if the composite reliability score $>0.7$ and AVE score $>0.5$ for each construct [8]. Table III exhibits the validity and the reliability of all constructs. Thus, the measurement model evaluation was accepted. 


\section{Evaluation of the structural model (inner model)}

The structural model in this study was developed based on Partial Least Square (PLS) SEM. To evaluate the structural model, the significance $\alpha$ was set to 0.05 . Table IV presents the $p$-value of the inner model. Based on the $p$-value and path analysis, achievement, enjoyment, fantasy, self-presentation, and social interaction variables had significant impacts on the continuance intention of playing MVG (all inner $p$-value were less than 0.05). On the other hand, escapism and social presence variables did not correspond to continuance intention (all inner $p$-value were greater than 0.05).

TABLE IV

INNER MODEL EVALUATION

\begin{tabular}{|c|c|c|c|c|c|c|}
\hline & $\begin{array}{c}\text { Original } \\
\text { Sample }(O)\end{array}$ & $\begin{array}{c}\text { Sample } \\
\text { Mean (M) }\end{array}$ & $\begin{array}{l}\text { Standard } \\
\text { Deviation } \\
\text { (STDEV) }\end{array}$ & $\begin{array}{c}\text { T Statistics } \\
(|\mathrm{O} / \mathrm{STDEV}|)\end{array}$ & $\begin{array}{c}\text { Path } \\
\text { coefficient } \\
(\beta \text {-value) }\end{array}$ & P-value \\
\hline $\mathrm{AC} \rightarrow \mathrm{CI}$ & 0.245 & 0.242 & 0.054 & 4.530 & 0.245 & 0.000 \\
\hline $\mathrm{EN} \rightarrow \mathrm{CI}$ & 0.276 & 0.277 & 0.054 & 5.114 & 0.276 & 0.000 \\
\hline $\mathrm{ES} \rightarrow \mathrm{CI}$ & 0.009 & 0.011 & 0.044 & 0.204 & 0.009 & 0.838 \\
\hline $\mathrm{FA} \rightarrow \mathrm{CI}$ & 0.098 & 0.096 & 0.047 & 2.114 & 0.098 & 0.035 \\
\hline $\mathrm{SEP} \rightarrow \mathrm{CI}$ & -0.116 & -0.104 & 0.046 & 2.524 & 0.116 & 0.012 \\
\hline $\mathrm{SI} \rightarrow \mathrm{CI}$ & 0.231 & 0.232 & 0.054 & 4.289 & 0.231 & 0.000 \\
\hline $\mathrm{SP} \rightarrow \mathrm{CI}$ & 0.078 & 0.078 & 0.057 & 1.353 & 0.078 & 0.177 \\
\hline
\end{tabular}

The second structural model evaluation incorporated age and gender variables as the moderators between behavioral motivation and continuance intention of playing MVG. The result is shown in Table V. According to the results, age moderated the effects of achievement, enjoyment, fantasy, self-presentation, and social interaction. Similarly, the moderation role of gender on achievement, enjoyment, fantasy, self-presentation, and social interaction variables was significant (all p-value were less than 0.05 ).

TABLE V

PATH ANALYSIS OF AGE AND GENDER MODERATION

\begin{tabular}{ccccc}
\hline \hline & \multicolumn{2}{c}{ Age moderation effect } & \multicolumn{2}{c}{ Gender moderation effect } \\
\cline { 2 - 5 } & Path coefficient $(\beta$-value $)$ & P-value & Path coefficient $(\beta$-value) & P-value \\
\hline $\mathbf{A C} \rightarrow$ CI & 0.245 & $\mathbf{0 . 0 0 0}$ & 0.245 & $\mathbf{0 . 0 0 0}$ \\
$\mathbf{E N} \rightarrow$ CI & 0.276 & $\mathbf{0 . 0 0 0}$ & 0.276 & $\mathbf{0 . 0 0 0}$ \\
$\mathbf{E S} \rightarrow$ CI & 0.009 & 0.835 & 0.009 & 0.830 \\
$\mathbf{F A} \rightarrow$ CI & 0.098 & $\mathbf{0 . 0 4 1}$ & 0.098 & $\mathbf{0 . 0 2 8}$ \\
$\mathbf{S E P} \rightarrow$ CI & -0.116 & $\mathbf{0 . 0 1 0}$ & -0.116 & $\mathbf{0 . 0 1 1}$ \\
$\mathbf{S I} \rightarrow$ CI & 0.231 & $\mathbf{0 . 0 0 0}$ & 0.231 & $\mathbf{0 . 0 0 0}$ \\
$\mathbf{S P} \rightarrow$ CI & 0.078 & 0.170 & 0.078 & 0.165 \\
\hline \hline
\end{tabular}

The subgroup analysis of the basic research (age and gender subgroups) model is shown in Table VI.

TABLE VI

SUBGROUP ANALYSIS OF THE BASIC RESEARCH

\begin{tabular}{cllcll}
\hline \hline & \multicolumn{3}{c}{ Age } & \multicolumn{2}{c}{ Gender } \\
\cline { 2 - 6 } & \multicolumn{1}{c}{$<\mathbf{1 6}-\mathbf{2 0}$} & $\mathbf{2 1 - 2 5}$ & Male & Female \\
\hline AC $\rightarrow$ CI & $\beta=0.357$, & $\beta=0.256$, & $\beta=0.114$, & $\beta=0.261$, & $\beta=0.120$, \\
& $p=0.202$ & $p=0.001$ & $p=0.111$ & $p=0.000$ & $p=0.146$ \\
EN $\rightarrow$ CI & $\beta=0.364$, & $\beta=0.225$, & $\beta=0.301$, & $\beta=0.202$, & $\beta=0.471$, \\
& $p=0.254$ & $p=0.002$ & $p=0.000$ & $p=0.001$ & $p=0.000$ \\
ES $\rightarrow$ CI & $\beta=-0.042$, & $\beta=-0.022$, & $\beta=0.078$, & $\beta=0.005$, & $\beta=0.047$, \\
& $p=0.880$ & $p=0.697$ & $p=0.249$ & $p=0.919$ & $p=0.607$ \\
FA $\rightarrow$ CI & $\beta=0.298$, & $\beta=0.068$, & $\beta=0.121$, & $\beta=0.098$, & $\beta=0.091$, \\
& $p=0.165$ & $p=0.322$ & $p=0.058$ & $p=0.058$ & $p=0.278$ \\
SEP $\rightarrow$ CI & $\beta=0.081$, & $\beta=-0.091$, & $\beta=-0.161$, & $\beta=-0.135$, & $\beta=0.066$, \\
& $p=0.784$ & $p=0.182$ & $p=0.235$ & $p=0.011$ & $p=0.672$ \\
SI $\rightarrow$ CI & $\beta=-0.143$, & $\beta=0.241$, & $\beta=0.228$, & $\beta=0.222$, & $\beta=0.177$, \\
& $p=0.592$ & $p=0.002$ & $p=0.004$ & $p=0.000$ & $p=0.158$ \\
SP $\rightarrow$ CI & $\beta=-0.007$, & $\beta=0.180$, & $\beta=0.025$, & $\beta=0.173$, & $\beta=-0.149$, \\
& $p=0.982$ & $p=0.020$ & $p=0.758$ & $p=0.009$ & $p=0.176$ \\
\hline \hline
\end{tabular}




\section{DISCUSSION}

\section{A. Factors affecting the continuance intention of playing $M V G$}

This study explores what factors influence game users to engage in playing multiplayer video games based on uses and gratifications theory. The inner model evaluation result is summarized in Fig. 2. The positive correlation in $\mathrm{H} 1$ and $\mathrm{H} 2$ shows that enjoyment and fantasy motivate the user to keep playing MVG. This type of game is a hedonic system that focuses on entertainment, therefore it is easy for the users to sense the enjoyment, such as when successfully striking the opponent, winning the competition, or accumulating rare items. This result is in line with prior studies that reported enjoyment affected user repurchase intention in online shopping [20], [21]. Likewise, MVG offers various storylines that enable the users to carry out activities that they cannot do in the real life and to pretend to be any characters (such as heroes, animals, fantasy creatures, celebrities, and soldiers). This finding in fantasy is similar to Kim et. al. study [22] that stated that fantasy is an important factor motivating the user engagement with an online game. In contrast with previous work, escapism does not affect the continuance intention of playing MVG in this study (H3). A possible explanation is some users play MVG as their occupation or to earn additional income, therefore playing MVG is part of their works and does not entirely cut off from reality.

In social gratification, only social interaction positively affects the continuance intention of playing MVG, as shown in H4. Users play MVG because they want to interact with other users in the game in various roles, for example as a competitor, a partner, or a mediator. MVG also provides communication channels and facilitates the community development. Interactions among the users and participation in MVG community may develop into a more intense relationships and could motivate the users to keep playing the game. On the other hand, social presence does not have a significant impact on the MVG continuance intention, as demonstrated by H5 rejection. Some users play MVG thoroughly for enjoyment and entertainment, thus they are not concerned with social attachment in the game.

The positive correlation in $\mathrm{H} 6$ and $\mathrm{H} 7$ reveals that the utilitarian gratification significantly influences the continuance intention of playing MVG. The main goal of playing MVG is related to achievement, such as finishing the game storyline with the highest score, acquiring rare game items, or defeating the opponent team. It brings the sense of satisfaction and the feeling of well-being. Longer game play and more accomplishments urge the users to achieve even higher success, thus prolonging their engagement with the game. This finding is similar with past works that mentioned achievement as one of the most important motivation to play video games [23] or online roleplaying games [24]. Lastly, self-presentation also motivates the user to play MVG. The game enables the user to develop a particular image that they aspire to be perceived for, for example as a proficient and likeable game player. User are willing to spend hours of time on playing the game to attain the desired self-presentation.

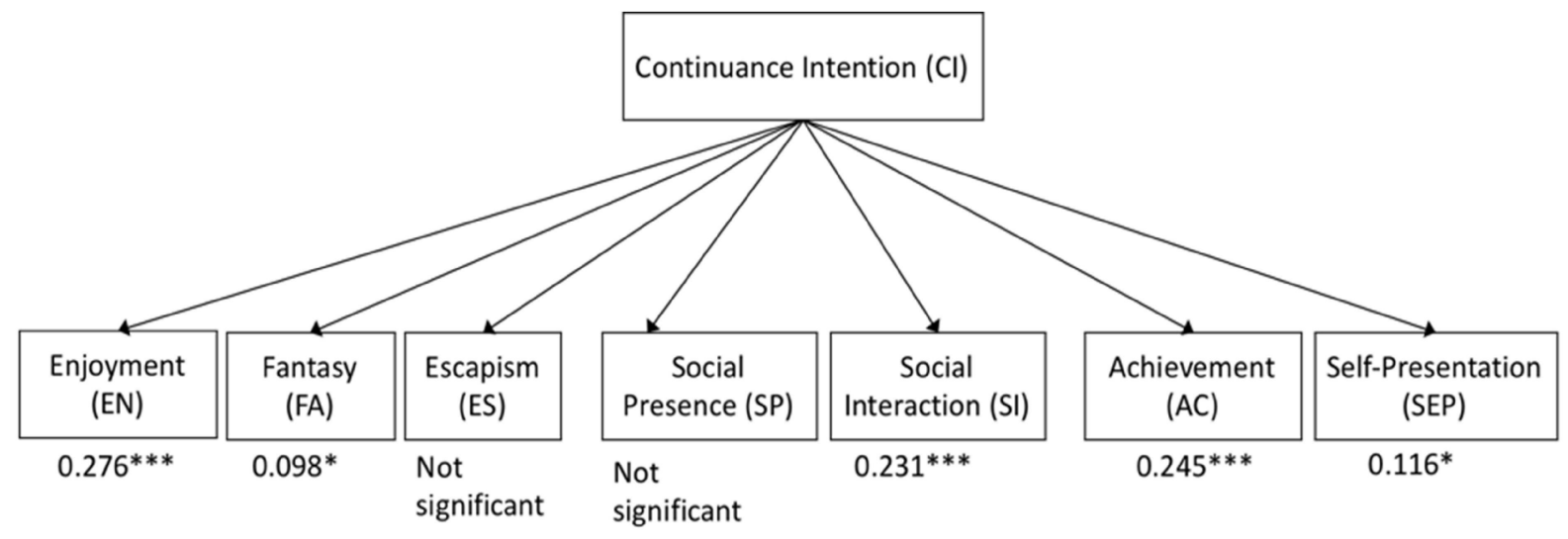

Note: ${ }^{*} p<0.05 ;{ }^{* *} p<0.01 ;{ }^{* *} p<0.001$

Fig. 2 Summary of inner model evaluation

The moderation effect of gender in this study is consistent with prior studies in online games [5]. According to the result in Table VI, enjoyment was found to have a stronger impact on the continuance intention in the female subgroup than in the male group. While in the male subgroup, the continuance intention is also affected by 
achievement, social interaction, and social presentation. This finding suggests that males are likely to be more engaged in playing MVG than females because their motivation is more extensive than just seeking enjoyment.

In term of age subgroups (see Table VI), the result reveals some interesting findings. Users between 16 to 20 years old are motivated by achievement, enjoyment, social interaction, and self-presentation. Achievement in this age subgroup is found to have a strongest impact because the users are much interested in collecting rare items, completing campaigns, and acquiring higher position in the virtual world. On the other hand, users in the $21-25$ years subgroup are influenced by enjoyment and social interaction on the MVG continuance intention. These users are more likely to play MVG for entertainment and relaxation, e.g., to reduce the stress at work and in daily life.

\section{B. Implication and Future Research}

In view of the increasing advance of multiplayer video games, as well as the considerable number of respondents $(n=453)$ acquired, this study offers beneficial contributions to the user's behavioral study in hedonic information systems, despite some of the hypotheses being not valid. The identified contributing variables on the MVG continuance intention can be adopted to other hedonic information systems and utilitarian information systems. It is important for other information systems, particularly business information systems, online commerce, and marketing systems, to ensure that their users and customers keep using the system because it determines the system success.

The first variable, enjoyment, can be incorporated in the information system development by analyzing user tasks and designing enjoyable user experiences. Likewise, fantasy draws users to utilize and to explore the system. Some examples of the fantasy implementation are emoji, virtual customer service, and profile avatar. The variable social interaction also invigorates the intention to keep using the system. Nowadays, collaborative and interconnected works have replaced the traditional ways to deliver superior results efficiently More software and applications are designed to facilitate collaborative works by implementing cloud-based platform, communication channels, and social networks. Users adhere to specific system to support their social interaction with other colleagues for completing their tasks.

Utilitarian gratifications play important roles in the system usage. The achievement variable should be considered in the system development. The more users acquire rewards, the longer they use the system. Some of the applications are giving away vouchers or gift cards for e-commerce users after they have spent a certain amount, membership tier and loyalty program, and releasing hidden features after users have acquired specific goals. The last variable, self-presentation, can be implemented in the rating system. Users continue use the system to enhance their rating for economic and social purposes. In resource sharing applications, such as Uber, AirBNB, and Gojek, both producers and consumers put efforts to maintain their excellent rating by keep using the system and providing better services. Higher rating enables more economic advantages and social opportunities.

While most of the results correspond to the goals of this study, a further validation is required. Future study should improve the data collection by involving larger respondents from various demographic profiles to acquire more significant results. The next improvement is investigating other moderating variables, such as occupation and income.

\section{CONCLUSIONS}

This study investigates the impact of users' gratifications on their continuance intention of playing MVG. The results of this study support two main conclusions. First, the influenced factors that support the MVG continuance intention are enjoyment, fantasy, social interaction, achievement, and self-presentation. Second, all three gratifications (hedonic, social, and utilitarian) affect the continuance intention in hedonic information systems. At the beginning of use, users tend to be influenced by hedonic and social gratifications. The more the users play MVG, the utilitarian gratification (achievement and self-presentation) becomes more significant as the users have achieved accomplishments that correspond to their utilitarian needs. The results and findings from this study offer additional insights into the system development to enhance the information system application.

\section{REFERENCES}

[1] H. van der van der Heijden, "User Acceptance of Hedonic Information Systems," MIS Q., vol. 28, no. 4, p. $695,2004$.

[2] D. Williams, N. Yee, and S. E. Caplan, "Who plays, how much, and why? Debunking the stereotypical gamer profile," J. Comput. Commun., vol. 13, no. 4, pp. 993-1018, Jul. 2008

[3] H. Jenkins, R. Purushotma, M. Weigel, K. Clinton, and A. J. Robison, Confronting the Challenges of Participatory Culture: Media Education for the 21st Century. Cambridge: The MIT Press, 2009.

[4] J. Hamari, N. Hanner, and J. Koivisto, "Service quality explains why people use freemium services but not if they go premium: An empirical study in free-to-play games," Int. J. Inf. Manage., vol. 37, no. 1, pp. 1449-1459, Feb. 2017. 
[5] H. Li, Y. Liu, X. Xu, J. Heikkilä, and H. van der Heijden, "Modeling hedonic is continuance through the uses and gratifications theory: An empirical study in online games," Comput. Human Behav., vol. 48, pp. 261-272, Jul. 2015.

[6] J.-B. E. M. Steenkamp and H. Baumgartner, "The Role of Optimum Stimulation Level in Exploratory Consumer Behavior," J. Consum. Res., vol. 19, no. 3, p. 434, Dec. 1992.

[7] J. Kim and H.-A. Park, "Development of a health information technology acceptance model using consumers' health behavior intention.," J. Med. Internet Res., vol. 14, no. 5, p. e133, Oct. 2012.

[8] I. Puspitasari and F. Jie, "Making the Information Technology (IT) Business Alignment Works: A Framework of IT-based Competitive Strategy," Int. J. Bus. Inf. Syst., vol. 34, no. 1, p. 1, 2020.

[9] K. J. Kim and S. S. Sundar, "Does screen size matter for smartphones? Utilitarian and hedonic effects of screen size on smartphone adoption.," Cyberpsychol. Behav. Soc. Netw., vol. 17, no. 7, pp. 466-73, Jul. 2014.

[10] S. Kim, K.-H. Lee, H. Hwang, and S. Yoo, "Analysis of the factors influencing healthcare professionals' adoption of mobile electronic medical record (EMR) using the unified theory of acceptance and use of technology (UTAUT) in a tertiary hospital," BMC Med. Inform. Decis. Mak., vol. 16, no. 1, p. 12, Dec. 2015.

[11] S.-S. Liaw and H.-M. Huang, "Perceived satisfaction, perceived usefulness and interactive learning environments as predictors to selfregulation in e-learning environments," Comput. Educ., vol. 60, no. 1, pp. 14-24, Jan. 2013.

[12] I. Puspitasari, "Stakeholder's expected value of Enterprise Architecture: An Enterprise Architecture solution based on stakeholder perspective," in 2016 IEEE/ACIS 14th International Conference on Software Engineering Research, Management and Applications, SERA 2016, 2016.

[13] T. E. Ruggiero, "Uses and Gratifications Theory in the 21st Century," Mass Commun. Soc., vol. 3, no. 1, pp. 3-37, Feb. 2000.

[14] P. Ifinedo, "Applying uses and gratifications theory and social influence processes to understand students' pervasive adoption of social networking sites: Perspectives from the Americas,” Int. J. Inf. Manage., vol. 36, pp. 192-206, 2016.

[15] J.-H. Wu, S.-C. Wang, and H.-H. Tsai, "Falling in love with online games: The uses and gratifications perspective," Comput. Human Behav., vol. 26, no. 6, pp. 1862-1871, Nov. 2010.

[16] L. Huang and Y. Hsieh, "Predicting online game loyalty based on need gratification and experiential motives," Internet Res., vol. 21, no. 5, pp. 581-598, Aug. 2011.

[17] J. Henseler and W. W. Chin, "A Comparison of Approaches for the Analysis of Interaction Effects Between Latent Variables Using Partial Least Squares Path Modeling," Struct. Equ. Model. A Multidiscip. J., 2010.

[18] C. Fornell and D. Larcker, "Evaluating structural equation models with unobservable variables and measurement error," J. Mark. Res., 1981.

[19] W. W. Chin, "How to Write Up and Report PLS Analyses," in Handbook of Partial Least Squares, 2010.

[20] C. Chiu, C. Chang, H. Cheng, and Y. Fang, "Determinants of customer repurchase intention in online shopping," Online Inf. Rev., vol. 33, no. 4, pp. 761-784, Aug. 2009.

[21] C. Wen, V. Prybutok, and C. Xu, "An integrated model for customer online repurchase intention," J. Comput. Inf. Syst., 2011.

[22] Y.-Y. Kim, M.-H. Kim, and S. Oh, "Emerging factors affecting the continuance of online gaming: the roles of bridging and bonding social factors," Cluster Comput., vol. 17, no. 3, pp. 849-859, Sep. 2014.

[23] C. M. Jones, L. Scholes, D. Johnson, M. Katsikitis, and M. C. Carras, "Gaming well: Links between videogames and flourishing mental health," Front. Psychol., 2014.

[24] M. Suznjevic and M. Matijasevic, "Why MMORPG players do what they do: Relating motivations to action categories," 2010. 